\title{
Философия
}

УДК 1:378.14(045)

\section{И.В. Журбина}

\section{ФИЛОСОФИЯ В ПОЛЕ ОБРАЗОВАТЕЛЬНЫХ УСЛУГ «ПРЕДПРИНИМАТЕЛЬСКОГО УНИВЕРСИТЕТА»}

В статье рассматривается проблема современного статуса философии в условиях коммерциализации высшего образования, превращающей университет в предпринимательскую организацию. Показано, что неолиберальная политика коммерциализации высшего образования радикально изменяет структуру образовательного процесса и подводит к пределу гуманизм как образовательную модель, неразрывно связанную с развитием гуманитарных дисциплин. В эпоху капитализации знания доминирующим становится принцип утилитаризма. Обосновывается необходимость преодоления неолиберальной тенденции и возвращения к гуманитарным дисциплинам, которые в современном мире сохраняют культуру человеческого мышления. Установлено, что построение процесса университетского образования по модели «бытия-в-месте» актуализирует мышление, возвращающее человека из инертности не мыслящего существования. Раскрывается специфика философии как практики мышления и языка, сохраняющая основы человеческого бытия и развивающая герменевтический тип мышления личности как реrsona. Герменевтический тип мышления ориентирован на самопонимание человеком самого себя как личности и способствует пониманию Другого, диалог с которым открывает возможность не только посмотреть на себя подругому, но и понять «точку зрения» Другого, тем самым открывая иной горизонт видения мира в целом.

Ключевые слова: неолиберализм, человеческий капитал, капитализация знания, гуманитарные науки, философия, герменевтический тип мышления, диалог.

DOI: $10.35634 / 2412-9550-2021-31-2-147-154$

\section{Введение}

Современное состояние университетского образования исследователи связывают с неолиберальной политикой коммерциализации высшего образования и «капитализации» знания, превращающей университет в предпринимательскую организацию (С. Фуллер [28]), то есть бюрократически организованную и потребительски ориентированную корпорацию (Б. Ридингс [21]). Неолиберализм распространяет экономическую модель поведения на все сферы жизни общества, которые никогда до этого не являлись экономическими, - образование, здравоохранение, культуру и т. д. В этом смысле неолиберализм трансформирует модель жизни, формируя представление о человеке как hото economicus. В соответствии с моделью homo economicus человек рассматривается как рационально действующее существо, приносящее своими действиями самому себе максимальную экономическую выгоду (М. Фуко [27. С. 285]). В эпоху неолиберализма любая деятельность начинает мыслиться исключительно в перспективе капитала и стоимости. Происходит эпистемологический сдвиг в понимании деятельности человека, чья жизнь представляется как особого рода бизнес-проект, ориентированный на формирование и постоянное увеличение человеческого капитала. «Неолиберализм - это больше, чем свобода рынка, это “форма, при которой обществом управляет экономика”» (А. Корсани [18. C. 176]).

В рамках неолиберализма знание становится производительной силой, производящей особого рода капитал - капитал знаний (А. Горц [10]). В результате образовательная система включается в процесс повышения стоимости человеческого капитала и выстраивается в соответствии с критериями экономической рентабельности. В современной социальной философии, с одной стороны, появляются концепции, показывающие перспективы дальнейшего развития университета в эпоху экономической организации мира, к которым относятся концепции «предпринимательского университета» (Б. Кларк [17]), «университета в условиях рынка» (Д. Бок [7]), «университета третьего поколения» (Й. Виссема [8]) и т. д. В данном случае коммерческая активность университетов рассматривается в перспективе увеличения и расширения источников финансирования высшего образования. Коммерциализация открывает возможности зарабатывать университетам деньги как на самом образовании, так и на экспертной деятельности и результатах научного знания (Д. Бок [7. С. 31]). С другой сторо- 
ны, активно развивается критическая традиция, не только анализирующая условия трансформации университетской системы в эпоху экономической глобализации, но и показывающая пределы неолиберальной модели университетского образования. К таким концепциям относится «капитализм знаний» (А. Горц [10]), «университет - это институт в руинах» (Б. Риддингс [21]), «макдональдизация общества» (Дж. Ритцер [22]), «прекариат - новый опасный класс» (Г. Стендинг [25]) и т. д. Эвристическая значимость этих концепций заключается в том, что исследователи, рассматривая современную систему университетского образования в перспективе предела, показывают необходимость пересмотра статуса гуманитарных дисциплин, утративших свое доминирующее положение в современном предпринимательском университете.

\section{Принцип экономической эффективности и качество образования в модели современного университета}

В настоящее время три идеи университета эпохи модерна - кантовская концепция разума, гумбольдтовская идея культуры и сегодняшняя технобюрократическая идея качества и/или совершенства не могут больше выступать фундаментом существования современного университета [21. С. 30]. В соответствии с неолиберальной политикой коммерциализации системы высшего образования университет подчиняется внешнему требованию экономической эффективности и законам рынка. Создаваемый университетами продукт начинает определяться стабильностью спроса. Рыночные критерии изменяют как процесс образования, так и саму концепцию университетского знания.

Университет, функционирующий по принципу коммерческого предприятия, выстраивает собственную бизнес-модель, суть которой заключается в том, что университет является одним из поставщиков образовательных услуг. Трансформируется общее отношение к знанию, в соответствии с которым традиционный вопрос «верно ли это?» заменяется уже иными вопросами: «чему это служит?» и «можно ли это продать?» (Ж.-Ф. Лиотар [19. С. 124]). Согласно требованиям рынка вузы должны постоянно увеличивать собственную прибыль за счет увеличения «пропускной способности». Критерием оптимальности учебного плана и выбираемых дисциплин становится рынок, где учебные дисциплины попадают в зависимость от того, насколько они будут продаваемы, то есть их оценивают по рыночным критериям: «соответствие спросу», «удовлетворение нужд работников», «предложения, обеспечивающего нужны финансового и промышленного капитала» и т. д. Однако в условиях рыночных отношений университеты вступают в конкуренцию с другими коммерческими организациями, предоставляющими образовательные услуги, и вновь появившимися новыми формами обучения, которые более приспособлены к условиям рынка и способны в сжатые сроки сформировать навык работы: повышение квалификации на рабочем месте, краткосрочные курсы повышения квалификации и семинары и т. д. Поскольку иные формы обучения сокращают временной промежуток между процессом приобретения необходимого знания и его применением на практике, потребители образовательных услуг нередко отдают предпочтение не полноценному университетскому образованию, а кратковременной профессиональной подготовке и/или переподготовке, ориентированной на конкретный вид деятельности, приносящей доход. «В таких условиях краткосрочная профессиональная подготовка, пройденная на рабочем месте под руководством работодателей, ориентированная непосредственно на конкретные виды деятельности, а также гибкие курсы и быстро обновляемые наборы материалов для самоподготовки, предлагающиеся на рынке без посредничества университетов, становятся более привлекательными $<\ldots>$, нежели полноценное университетское образование, которое неспособно сегодня даже обещать, не говоря о том, чтобы гарантировать пожизненную карьеру» [6. С. 165].

Данная тенденция порождает ощущение, что университеты становятся местом временного убежища для молодых людей, которые по каким-либо причинам сразу после школы не смогли найти работу. Учеба в университете откладывает столкновение молодых людей с реалиями современного рынка труда, а именно с полной или частичной безработицей. Неолиберальная политика в сфере высшего образования создает парадоксальную ситуацию: чем выше уровень безработицы внутри общества, тем больше увеличивается спрос на университетское образование, особенно на платные формы образования и/или образование на коммерческой основе. Само университетское образование превращается в процесс конвейерного обслуживания (Дж. Ритцер [22]). Академическая эффективность сводится к количественным показателям, добиться которых позволяют компьютеризированное 
Философия в поле образовательных услуг «предпринимательского университета»

149 СЕРИЯ ФИЛОСОФИЯ. ПСИХОЛОГИЯ. ПЕДАГОГИКА

2021. Т. 31, вып. 2

тестирование, в рамках которого мышление оценивается по степени быстроты реагирования студента на вопрос, и компьютеризированные экзамены.

Неолиберальная политика в системе высшего образования вырабатывает особое утилитарное отношение к знанию, в соответствии с которым потребитель образовательных услуг выбирает только то знание, которое поддается «капитализации» [4. С. 79]. В этом смысле сформировать человеческий капитал означает формировать те виды компетенций - знания («знать»), навыки («уметь») и способности («уметь-быть»), - которые могут проносить доход. Тенденция к утилитарности приводит к тому, что знание перестает быть показателем интеллектуальности и интеллекта, оно приобретает исключительно прикладной характер. В системе высшего образования повышенным спросом начинают пользоваться только те предметы, которые в дальнейшем возможно успешно «капитализировать»: английский язык, компьютерное обучение, предпринимательство и/или экономика. Неолиберальное государство дает понять, что «высшее образование должно стать еще более экономически оправданным. Искусство и общественные науки - вещи не обязательные» (Г. Стендинг [25. С. 146]). В этом смысле неолиберализм манифестирует завершение эры гуманизма как обучающей и образовательной модели, которая исторически неразрывно связана с развитием таких гуманитарных дисциплин, как история, литература, поэзия, грамматика, философия, формирующих представление о Человеке, мышлении, языке и культуре в целом.

При этом необходимо заметить, что принцип экономической эффективности вступает в противоречие с внутренним требованием повышения качества университетского образования. Экономическая логика спроса и предложения приводит к тому, что вузы становятся производителями стандартизированного товара. Система высшего образования упрощается настолько, что, с одной стороны, университеты начинают выдавать дипломы по несуществующим специальностям: «путешествие с философской мотивацией» (Плимутский университетский колледж св. Марка и св. Иоанна), «организации стиля жизни» (Городской университет Лидса) [25. С. 144]. С другой стороны, университеты предлагают псевдонаучные курсы: рефлексология, ароматерапия, акупунктура, фитотерапия и т. д. Повышение процента успешно сдавших экзамены студентов достигается за счет упрощения курсов и самой процедуры принятия экзаменов.

В вузах начинают активно продвигать идеи «обучения без преподавателя» и «аудитории без преподавателя», а исследователи активно обсуждают перспективы массовых открытых онлайнкурсов в России (Р. Штайн [30], Т.В. Семенова, К.А. Вилкова, И.А. Щеглова [23], У.С. Захарова, К.И. Танасенко [13]). Массачусетский технологический институт запустил проект Open Courseware Consortium, в рамках которого в Интернете публикуются бесплатные онлайн-курсы, в том числе лекции преподавателей, видеоуроки и экзаменационные вопросы. Портал iTunes предлагает лекции из Беркли, Оксфорда и других учебных заведений. Народный университет (University of the People), ocнованный израильским предпринимателем, предлагает получить диплом бакалавра без помощи преподавателей, посредством взаимного обучения: студенты учатся не у преподавателей, а у таких же студентов, обмениваясь вопросами и ответами в режиме онлайн. «Сторонники товаризации уверяют, что она якобы “делает потребителей ответственными”» [25. С. 141].

Система образования выстраивается на негласном соглашательстве, вынуждающем преподавателей и студентов приспосабливаться внутри вуза к условиям рыночной экономики. Пределом такого соглашательства становится создание видимости процесса обучения. Современную систему университетского образования, считает Г. Стендинг, можно описать фразой из старого советского анекдота: «Они делают вид, что обучают нас, а мы делаем вид, что учимся» [25. С. 147].

\section{Социально-политические последствия коммерциализации высшего образования: молодежь - ядро прекариата}

Стремясь занять в профессии устойчивое положение, то есть найти престижную работу, в соответствии с полученным образованием, молодые люди соглашаются на низкоквалифицированные должности, не требующие приобретенных в университете знаний и навыков, бесперспективную работу, не предполагающую дальнейшего карьерного роста, краткосрочные формы занятости - испытательный срок, временные должности, стажерство как искусственный вид занятости, который не столько развивает профессиональные навыки, сколько скрывает состояние безработицы. Образование, превращенное в товар, способствует появлению массовой депрофессионализации среди молоде- 
жи. «Это особенно наглядно проявляется в судьбе выпускников университетов и других учебных заведений (из них в основном комплектуется офисный планктон), занятость которых мало различает и учитывает прежнюю подготовку молодых людей. Большинство из них, несмотря на ранее полученную специальность, выполняет некий набор усредненных требований, необходимых для исполнения таких функций, как справки, подготовка исходной информации, сбор необходимых данных, выполнение поручений, для реализации которых не обязательно иметь высшее образование. В этих условиях становится важным наличие диплома об образовании без особого учета, какое это образование и в чем оно заключается, какую профессию получил молодой человек» [26. С. 7-8].

Молодежь с высшим образованием становится ядром нового социального класса - прекариата, который является следствием экономической глобализации мира. Экономическая глобализация модель устойчивой занятости и «защищенного труда» заменяет на модель «гибкого рынка труда», деформирующую рынок труда в целом. Введенное в научный оборот П. Бурдье понятие «прекариат» является по своей сути неологизмом, образованным от соединения двух слов: английского precarious, означающего «неустойчивый», «ненадежный», и латинского proletarius (пролетариат). В настоящее время исследователи к прекариату относят категории населения, не имеющие стабильного дохода, среди которых приоритет принадлежит молодежи с высшим образованием.

В условиях гибкого рынка труда высокооплачиваемая работа, соответствующая полученному диплому, становится для молодежи идеальным объектом желания, функционирующим по принципу Das Ding (C. Жижек). Получение бесперспективной работы, временной должности, работы с испытательным сроком порождает у молодежи разочарование. Чувство разочарования, с одной стороны, оказывается движущей силой выстраивания дальнейших образовательных стратегий молодежи краткосрочная профессиональная переподготовка, курсы повышения квалификации и переквалификации, которые изначально вписаны в процесс коммерциализации образования. Образовательная стратегия молодежи с высшим образованием идет по пути увеличения количества дипломов и сертификатов. При этом процесс бесконечного обучения скрывает отсутствие реальной перспективы получить высокооплачиваемую работу.

С другой стороны, разочарования порождают более радикальное чувство, а именно чувство социальной несправедливости, которое имеет политические последствия, поскольку превращает молодежь в движущую силу «политики улиц» (Дж. Батлер [5]). Участником современных стихийных выступлений - уличных манифестаций и акций протеста - является прекариат, состоящий в основном из молодежи: «недовольство копится также среди той части молодых интеллектуалов, которые внешне благополучны, устроены, но не чувствуют гарантированной стабильности, возможности строить профессиональную карьеру и обеспечить себе защищенное будущее» [26. С. 11].

Активность вовлечения молодежи в «политику улиц» объясняется не только внутренним состоянием незащищенности труда, неуверенностью в завтрашнем дне и общим чувством неудовлетворенности, но и неспособностью осмыслить жизненные перспективы, которая является следствием отсутствия практики мышления. Если университет эпохи модерна выстраивался на идеалах разума (ratio), когда человек приобретал свободу мышления, то понижение качества образования и принцип утилитаризма способствуют инфантилизации мозгов и появлению синдрома дефицита внимания, свойственного прекаретизированному мышлению [25. С. 143]. В современном «предпринимательском университете» утрата гуманитарными науками своего доминирующего положения привела к тому, что университет больше не учит искусству мышления. Важнейшей характеристикой современной системы образования становится «забвение» (М. Хайдеггер) Мышления, с большой буквы, то есть Мышления, которое мыслит, а значит, ставит вопросы, являясь по своей сути вопрошающим мышлением.

\section{Дисциплина «философия» в эпоху «капитализации» знания}

В поле образовательных услуг современного университета принцип утилитаризма обнаруживает предел в философии как дисциплине, знание которой невозможно «капитализировать» в прямом смысле этого слова. В поле образовательных услуг приоритет отдается узкопрофессиональным дисциплинам. Доминирование частных дисциплин, повышающих профессиональный уровень студента, актуализирует вопрос «зачем студенту философия?» (С.Б. Кондратьева [16]), который возвращает исследователей к проблеме осмысления статуса дисциплины философии в современной системе высшего образования. Профессиональное сообщество преподавателей философии и философов вновь 
Философия в поле образовательных услуг «предпринимательского университета»

задается вопросом: «что такое философия?», определяя философию, во-первых, как дисциплину, исследующую взаимоотношения Человека с Миром на уровне онтологии, гносеологии, антропологии и социальной философии (В.В. Миронов [20. С. 26]), во-вторых - как дисциплину, формирующую теоретические основы мировоззрения и участвующую в воспитании гражданина (Н.С. Кирабаев [15. С. 27]), в-третьих - как дисциплину, препятствующую процессу полной деинтеллектуализации высшего образования (С.Б. Кондратьева [16]), в-четвертых - как дисциплину, развивающую навыки критического мышления (В.М. Карелин, Н.И. Кузнецова, И.Н. Грифцова [14. С. 67]).

В университете, функционирующем по законам рынка, философские факультеты постепенно «превращаются в прикладные отделения, на которых эксперты предоставляют omвembl, а не работают над вопросами» [21. С. 273]. Неолиберальная модель университета, ориентированная на экономическую эффективность, считает Б. Ридингс, обнаруживает собственную неэффективность в том, что она исключает Мышление, делая его все менее необходимым и ненужным. Отсутствие Мышления позволяет в полной мере реализовать призыв «Действуй!», который показывает, что Мышление и Действие являются разнонаправленными процессами. Чем больше человек думает/размышляет, тем меньше homo economicus остается возможности совершить действие, направленное на увеличение человеческого капитала. В таком университете Мышление «соотносится скорее с экономикой траты, чем с ограниченной экономикой расчета. Мышление - это непродуктивный труд, и поэтому в балансовых отсчетах оно фигурировало бы лишь в графе убытков» [21. С. 276]. Сохранить Мышление в Университете возможно только тогда, когда рынок курсов сам станет предметом Мышления, а мышление окажется формой-жизни (Дж. Агамбен [1. С. 22]) университетского сообщества, со-в-местный процесс Мышления которого откроет пространство бытия-в-месте [21. С. 299].

Основная задача, которая стоит перед современным университетом, заключается в том, чтобы не просто развивать способность мыслить, но развивать вопрошающее мышление, ориентированное не на получение готовых ответов, а на постановку вопросов. Диалоги Платона, суть которых составляют сократические беседы, вопросы И. Канта «что я могу знать?», «что я должен делать?», «на что я могу надеяться?», «что такое человек?», концепция «вопрошающей философии» М. Хайдеггера показывают, что человеческая мысль живет только в вопросах и прежде всего в вопросах о бытии. Основной тезис Сократа - «познай самого себя, и ты познаешь весь мир» - обращает человека к самому себе с вопросом «что я знаю?», открывающим возможности человеческого мышления. Философия М. Хайдеггера всегда начинается с вопросов, она «учит вопрошать и постоянно находиться в этом вопрошании» [11. С. 67].

Особенностью дисциплины философия является то, что она имеет минимальную меновую стоимость, но при этом предоставляет человеку намного больше, чем какое-либо другое знание. Можно говорить о том, что философия не только учит мыслить, но сама является практикой мышления, радикальная нехватка которой обнаруживает себя в современной системе университетского образования. В данном аспекте история философии представляется историей человеческой мысли (О.А. Власова [9. С. 100]), ведущей диалог с традицией, а философия понимается как процесс философст-

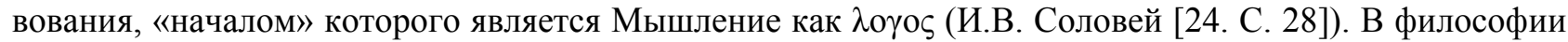
«мыслить означает расспрашивать и вопрошать» [3. С. 150]. Именно философия рассматривает мышление как форму действия, обращающего человека к самому себе с фундаментальными вопросами. В философии Аристотеля мышление как действие определяется словом $\pi \rho \tilde{\alpha} \xi_{1} \zeta$. «Мысль действует, пишет М. Хайдеггер, - поскольку мыслит» [29. С. 192]. В этом смысле философия является абсолютно практической дисциплиной, поскольку является практикой мысли и мышления. Человек мыслит лишь тогда, когда не забывает о том, «что зовется мышлением» (М. Хайдеггер), но это знание открывает именно философия.

Греческое слово к знанию» или «стремление к пониманию», можно трактовать и как стремление к мышлению, поскольку, начиная с античной философии, мудрость (бофі́ $\alpha$ ) рассматривается как высшая форма мышления $[4,1177 b-20$. С. 268-269]. Здесь мышление тождественно созерцательной активности, которая существует «сама ради себя», то есть является чистой актуальностью, не имеющей конечной цели и не оставляющей никакого конечного результата, кроме себя самой (И.В. Журбина [12. С. 18]).

Философский способ действия заключается в постановке вопросов, которые «захватывают» спрашивающего, предъявляя человека как вопрошающе-понимающее существо. «Философское мышление каждый раз должно начинаться с самого начала. Каждый человек должен осуществлять его 
самостоятельно» (К. Ясперс [12]). Философия, начиная с Сократа, учит в первую очередь общению с самим собой - «как мыслить» и «как говорить с самим собой», чтобы понять самого себя. Задавая вопрос самому себе, человек вступает в диалог с самим собой. В структурах диалогического мышления, считает X. Арендт, человек пребывает вместе с кем-то, а именно с самим собой, где он представляется «два-в-одном»: «нигде так ясно не проявляется я-с-собой, как в чистом мышлении; это всегда диалог между теми двумя, которые составляют мое “я”» [2. С. 164]. Диалогическая природа мышления позволяет переходить от внутреннего и/или беззвучного диалога с самим собой к внешнему диалогу, ориентированному на понимание слова Другого. Вступая в диалог с Другим, человек начинает рассматривать себя по-другому, расширяя горизонт понимания мира и своего места в этом мире.

Диалогическое мышление, ориентированное на понимание не только себя, но и Другого, способствует становлению личности. Этимологически слово «личность», или «персона», обращает к латинскому persona, первоначально означающему маску актера. «Но в этой маске <...> имелось широкое отверстие в области рта, через которое звучал индивидуальный незамаскированный голос актера. Именно отсюда возникло существительное persona: оно образовалось от глагола per-sonare, “"звучать сквозь”» [3. С. 44-45]. В этом смысле определение человека как persona радикально отличается от hoтo, означающего просто человеческое существо, отличающееся от животного, но не имеющего никакого особого статуса. В данном случае homo economicus можно трактовать как понятие, обозначающее разумное существо, утратившее навык мыслить и/или не видящее необходимости понимать как самого себя, так и других, чье рациональное поведение является скорее свидетельством привычки действовать определенным образом.

Таким образом, неолиберальная политика коммерциализации высшего образования радикально изменяет структуру образовательного процесса и трансформирует смысл концепции знания, которое перестает рассматриваться в качестве самоцели и приобретает утилитарный характер. Неолиберальная модель университета, ориентированная на экономическую эффективность, обнаруживает собственную неэффективность в том, что она исключает Мышление, с большой буквы. Нехватка мышления, традиционно считающегося «делом философии», позволяет пересмотреть статус дисциплины философии в поле образовательных услуг современного «предпринимательского университета». В современной системе университетского образования философию можно рассматривать в качестве практической дисциплины, знание которой («знать»), формирует навыки («уметь») мышления и способность («уметь-быть») вести диалог не только с самим собой, но и с другими.

\section{СПИСОК ЛИТЕРАТУРЫ}

1. Агамбен Дж. Средства без цели. Заметки о политике / пер. итал. Э. Саттарова. М.: Гилея, 2015.148 с.

2. Арендт Х. Философия и политика // История философии. Вып. 13. М.: ИФ РАН, 2008. С. 153-180.

3. Арендт Х. Ответственность и суждение / пер. с англ. Д. Аронсона, С. Бардиной, Р. Гуляева. М.: Изд. Института Гайдара, 2013. 352 с.

4. Аристотель. Никомахова этика / пер. с древнегреч. Н.В. Брагинской // Аристотель. Этика. М.: АСТ: Астрель, 2011. 492 c.

5. Батлер Дж. Заметки к перформативной теории собрания. М.: Ад Маргинем Пресс, 2018. 248 с.

6. Бауман 3. Индивидуализированное общество. М.: Логос, 2002. 390 с.

7. Бок Д. Университеты в условиях рынка. Коммерциализация высшего образования / пер. с англ. С. Карпа. М.: Изд. дом Высшей школы экономики, 2012. 224 с.

8. Виссема Й. Университет третьего поколения. Управление университетом в переходный период / пер. с англ., науч. ред. В.С. Катькало. М.: Олимп-Бизнес, 2016. 432 с.

9. Власова О.А. Статус истории философии в общегуманитарном поле и университетской системе: перспектива самосознания // Science for Education Today. 2019. T. 9. № 4. С. 93-105.

10. Горц А. Нематериальное. Знание, стоимость и капитал / пер. с фр. и нем. М. Сокольской. М.: Издательский дом Гос. ун-та Высшей школы экономики, 2010. 208 с.

11. Долгов К.М. От Киркегора до Камю. Очерки европейской философско-эстетической мысли ХХ века. М.: Искусство, 1990. 399 с.

12. Журбина И.В. Концепция политического общения Аристотеля в контексте «лингвистического поворота» // Вестн. Удм. ун-та. Сер. Философия. Психология. Педагогика. 2020. Т. 30, вып. 1. С. 11-20.

13. Захарова У.С., Танасенко К.И. МООК в высшем образовании: достоинства и недостатки для преподавателей // Вопросы образования. 2019. № 3. С. 176-202. URL: https://www.elibrary.ru/item.asp?id=39555190 
14. Карелин В.М., Кузнецова Н.И., Грифцова И.Н. «Философия» как учебный курс: смена концепта // Высшее образование в России. 2017. № 10. С. 64-74.

15. Кирабаев Н.С. Воспитание гражданина: о преподавании философии в высших учебных заведениях России // Вопросы философии. 2018. № 6. С. 19-33.

16. Кондратьева С.Б. Зачем студенту философия: проблемы преподавания философии в высшей школе // Проблемы современного образования. 2018. № 2. С. 27-32.

17. Кларк Б.Р. Создание предпринимательских университетов: организационные направления трансформации / пер. с англ. А. Смирнова. М.: Изд. дом ВШЭ, 2011. 240 с.

18. Корсани А. Капитализм, биотехнонаука и неолиберализм // Горц А. Нематериальное. Знание, стоимость и капитал. М.: Издательский дом Гос. ун-та Высшей школы экономики, 2010. С. 162-192.

19. Лиотар Ж.-Ф. Состояние постмодерна. М.: Институт экспериментальной социологии; СПб.: Алетейя, 1998. $160 \mathrm{c}$.

20. Миронов В.В. О школьном образовании, гуманитарном знании и уровнях изучения философии // Вопросы философии. 2018. № 6. С. 19-33.

21. Ридингс Б. Университет в руинах / пер. с англ. А.М. Корбута. М.: Изд. дом Высшей школы экономики, 2021. $304 \mathrm{c}$.

22. Ритцер Дж. Макдональдизация общества 5 / пер. с англ. А. Лазарева. М.: Издательская и консалтинговая группа «Праксис», 2011.592 с.

23. Семенова Т.В., Вилкова К.А., Щеглова И.А. Рынок массовых открытых онлайн-курсов: перспективы для России // Вопросы образования. 2018. № 2. С. 173-197. URL: https://www.elibrary.ru/item.asp?id=35203143

24. Соловей И.В. Учебно-методические материалы к лекции «Введение в философию как философствование» // Вестник Удмуртского университета. Философия. Психология. Педагогика. 2016. № 4. С. 28-32.

25. Стендинг Г. Прекариат: новый опасный класс. М.: Ад Маргинем Пресс, 2014. 328 с.

26. Тощенко Ж.Т. Прекариат: новый социальный класс // Социологические исследования. 2015. № 6. С. 3-13.

27. Фуко М. Рождение биополитики. Курс лекций, прочитанных в Коллеж де Франс в 1978-1979 учебном году / пер. с фр. А.В. Дьякова. СПб.: Наука, 2010. 448 с.

28. Фуллер С. В чем уникальность университетов? Обновление идеала в эпоху предпринимательства / пер. С.Р. Филоновича // Вопросы образования. 2005. № 2. С. 50-76.

29. Хайдеггер М. Письмо о гуманизме // Хайдеггер М. Время и бытие: Статьи и выступления / пер. с нем. В.В. Бибихина. М.: Республика, 1993. С. 192-220.

30. Штайн Р. Поддержка онлайн-инициатив в образовании // Вопросы образования. 2018. № 4. С. 188-198.

31. Ясперс К. Введение в философию [Электронный ресурc]. URL: http://www.gumer.info/bogoslov_Buks/Philos/ yasp/vvedfil.php

Поступила в редакцию 13.03.2021

Журбина Ирина Викторовна, кандидат философских наук, доцент, доцент кафедры истории, теории и практики социальных коммуникаций

ФГБОУ ВО «Удмуртский государственный университет»

426034, Россия, г. Ижевск, ул. Университетская, 1 (корп. 4)

E-mail: soloveyiv1@mail.ru

\section{I.V. Zhurbina \\ PHILOSOPHY IN THE FIELD OF EDUCATIONAL SERVICES PROVIDED BY THE UNIVERSITY AS A BUSINESS}

DOI: $10.35634 / 2412-9550-2021-31-2-147-154$

The paper discusses the status of philosophy in the context of the increasing commercialization of higher education, which turns the university into a business. It shows that the neoliberal policy of the commercialization of higher education changes the structure of the educational process dramatically and brings humanism as an educational model inextricably linked with the development of humanitarian disciplines to the limit. In the era of capitalization of knowledge, the principle of utilitarianism becomes dominant. The paper gives reasons for the need to overcome the neoliberal tendency of the educational process dehumanization and return to humanitarian disciplines, which preserve the culture of human thinking in today's world. The paper finds that the construction of the process of university education according to the being-in-place model actualizes thinking, which brings an individual back from the inertia of non-thinking existence. The paper describes specificity of philosophy as a practice of thinking and language which preserves the foundations of human existence and develops the hermeneutic type of thinking of an individual as "persona". The hermeneutic 
type of thinking is focused on a person's self-understanding of oneself as a personality. At the same time, it contributes to understanding the Other, a dialogue with whom opens up the opportunity not only to look at oneself in a different way, but also to understand the "point of view" of the Other, thereby opening up a different horizon of seeing the world in general.

Keywords: neoliberalism, human capital, knowledge capitalization, humanities, philosophy, hermeneutic type of thinking, dialogue.

Received 13.03.2021

Zhurbina I.V., Candidate of Philosophy, Associate Professor

at Department of History, Theory and Practice of Social Communications, Institute of Social Communication Udmurt State University

Universitetskaya st., 1/4, Izhevsk, Russia, 426034

E-mail: soloveyiv1@mail.ru 